\title{
Taurolidine and oxidative stress: a rationale for local treatment of mesothelioma
}

\author{
N. Aceto*,\#, P. Bertino*, D. Barbone*, , G. Tassi ${ }^{+}$, L. Manzo ${ }^{\S}$, C. Porta ${ }^{f}$, \\ L. Mutti**,\#\# and G. Gaudino*,\#\#
}

ABSTRACT: Malignant mesothelioma is an asbestos-related, aggressive tumour, resistant to most anticancer therapies. Akt is a key mediator of mesothelioma cell survival and chemoresistance. This study aimed to clarify the mechanism by which taurolidine (TN), a known synthetic compound with antimicrobial and antineoplastic properties, leads to mesothelioma cell death.

Apoptosis was studied by annexin $\mathrm{V}$ binding, cell cycle analysis, caspase-8 activation, poly(ADP-ribose) polymerase (PARP) cleavage and terminal deoxynucleotidyl transferasemediated deoxyuridine triphosphate nick-end labelling (TUNEL). Oxidative stress was measured by nitrite production and DNA oxidative damage. Protein expression and phosphorylation were evaluated by immunoprecipitation and immunoblotting.

TN induces cell death of mesothelioma cells, but not of non-neoplastic human mesothelial cells. After TN treatment of mesothelioma cells, Akt but not extracellular signal-regulated kinase (Erk) 1/ 2 activity is inhibited a in time- and dose-dependent manner. Protein phosphatase (PP) $1 \alpha$ and PP2A are activated several hours after drug addition. Apoptosis induced by TN is driven by oxidative stress and cell exposure to sulfydryl donors, such as glutathione monoethylester and L-N-acetylcysteine, significantly reduced pro-apoptotic effects and Akt inhibition. Conversely, expression of constitutively activated Akt did not affect cytoxicity elicited by TN, which retained its ability to inhibit the kinase.

TN induces mesothelioma cell death via oxidative stress, accompanied by inhibition of Akt signalling. This provides a promising molecular rationale for TN as local treatment of malignant mesothelioma.

KEYWORDS: Akt, apoptosis, malignant mesothelioma, oxidative stress, taurolidine

M alignant mesothelioma is an asbestosrelated malignant tumour. Due to its biological aggressiveness, this cancer is constantly fatal, except in rare, less-advanced cases, with a median survival of 12.6 months [1].

The continuing increase in mesothelioma incidence has been associated with the widespread use of asbestos in the past century, even if genetic predisposition may render some individuals more susceptible [2]. Moreover, SV40, present in polio vaccines distributed in many countries, behaves as a co-carcinogen, causing malignant transformation of human mesothelial cells (HMCs) [3] through Akt-dependent survival signalling $[4,5]$.

Taurolidine (TN), or bis(1,1-dioxoperhydro-1,2,4thiodiazinyl-4)-methane, is an antibacterial drug originally synthesised in 1970 with activity against a broad spectrum of microorganisms and has been used as a safe lavage antibiotic to prevent bacterial infection in patients after abdominal surgery [6].

Over recent years, in vitro evidence has highlighted the role of TN as a pro-apoptotic and antiangiogenic agent and as an inhibitor of protein biosynthesis $[7,8]$. Some of these in vitro effects were also observed in brain tumour cells, whereas normal cells were unaffected [9]. Moreover, intraperitoneal administration of TN in experimental rats inhibited the growth of injected ovarian and colon cancer cells [10] Safety and efficacy of intracavitary administration of TN, along with a prolonged i.v. administration has been proposed to treat human tumours [11] and indicates that this drug is of potential help for therapy of tumours with prevalent local spreading, such as peritoneal and pleural mesothelioma.

The importance of the Akt pathway in maintaining anti-apoptotic survival signals, responsible
AFFILIATIONS

*DISCAFF Dept and DFB Center,

University of Piemonte Orientale "A. Avogadro", Novara,

${ }^{+}$Chest Medicine Unit, Brescia Hospital, Brescia,

${ }^{\text {s}}$ Dept of Toxicology, University of Pavia,

${ }^{f}$ Medical Oncology, IRCCS San

Matteo University Hospital, Pavia,

**Local Health Unit 11, Piemonte,

Borgosesia, Italy.

\#Friedrich Mietscher Institute, Basel, Switzerland

"Lung Biology Center, SFGH, UCSF,

San Francisco, CA, USA.

\#\# L. Mutti and G. Gaudino

contributed equally to this work.

CORRESPONDENCE

G. Gaudino

Dept of Chemical, Food,

Pharmaceutical and Pharmacological

Sciences and Drug and Food

Biotechnology Center

University of Piemonte Orientale "A.

Avogadro"

Via Bovio 6

28100 Novara

Italy

E-mail: giovanni.gaudino@unipmn.it

Received:

July 052008

Accepted after revision:

May 062009

First published online:

May 212009 
for onset and progression of mesothelioma, has been demonstrated [4, 12] and very recently we showed that addressing Akt with pharmacological agents is also a promising approach for mesothelioma $[13,14]$.

Oxidative stress generated by reactive oxygen species has been indicated both as a negative regulator of the survival factor Akt in human leukaemia cells [15] and as one of the effects elicited by $\mathrm{TN}$ in glioma cells, leading to suppression of VEGF production and to cell death [16].

We show here that TN specifically targets mesothelioma cells, but not non-neoplastic HMCs, and that its pro-apoptotic mechanism is mostly driven by oxidative stress and inhibition of Akt activity.

\section{METHODS}

\section{Cell cultures}

We used two human mesothelial non-neoplastic cell lines (HMC and MET5A) and two established human malignant mesothelioma cell lines (MMB and MMP). As controls we used human dermal fibroblast (HDF) and human lung carcinoma (A549). Primary HMCs were obtained from patients with congestive heart failure and cultured in Ham's F12 medium (Sigma-Aldrich, St. Louis, MO, USA) supplemented with $10 \%$ fetal bovine serum (FBS; Life Technologies, Rockville, MD, USA). MET5A were purchased from the American Type Culture Collection (ATCC; Manassas, VA, USA), and cultured in Medium 199 (Sigma-Aldrich) supplemented with 10\% FBS. MMB and MMP cells were derived from pleural effusions of malignant mesothelioma patients and cultured in Ham's F12 medium supplemented with $10 \%$ FBS. HDF were obtained from a healthy donor and cultured in Ham's F12 medium supplemented with 10\% FBS. A549 were purchased from ATCC and cultured in Ham's F12 medium supplemented with $10 \%$ FBS. Cells were grown at $37^{\circ} \mathrm{C}$ in a $5 \% \mathrm{CO}_{2}$-humified atmosphere. MyrAkt-MMB were obtained by transfecting MMB cells with Addgene plasmid 9008 (pcDNA3 myr-HAAkt1), using lipofectamine 2000. Transfectants were selected by $\mathrm{G} 418$ for 3 weeks.

\section{Chemicals}

Glutathione mono-ethylester (GSH), N-acetyl-L-cysteine (L-NAC) and rapamycin were purchased from Sigma-Aldrich.

\section{Cytofluorimetric analysis of apoptosis}

Subconfluent cells were exposed to $100 \mu \mathrm{M}$ TN (Taurolin ${ }^{\circledR}$; Geistlich Pharma, Wolhussen, Switzerland) or CD95-activating antibody $100 \mathrm{ng} \cdot \mathrm{mL}^{-1}$ (clone CH11; Upstate Biotechnology, Lake Placid, NY, USA). After 24-h incubation, cells were harvested in binding buffer $(10 \mathrm{mM}$ Hepes/NaOH $\mathrm{pH} 7.4$, $140 \mathrm{mM} \mathrm{NaCl}, 2.5 \mathrm{mM} \mathrm{CaCl} 2$ ), stained in the dark for $10 \mathrm{~min}$ with $5 \mu \mathrm{L}$ of fluoroscein isothiocyanate-labelled annexin $\mathrm{V}$ (Alexis, Lausanne, Switzerland), washed with binding buffer and then stained with $1 \mu \mathrm{g} \cdot \mathrm{mL}^{-1}$ propidium iodide (SigmaAldrich). We analysed 5,000 events per sample. Apoptotic cells were positive to annexin $\mathrm{V}$ staining only and late apoptotic cells were positive to both annexin $\mathrm{V}$ and propidium iodide staining.

\section{Terminal deoxynucleotidyl transferase-mediated deoxyuridine triphosphate nick-end labelling analysis}

Apoptosis was evaluated by terminal deoxynucleotidyl transferase-mediated deoxyuridine triphosphate nick-end labelling (TUNEL) analysis (DeadEnd ${ }^{\mathrm{TM}}$ Colorimetric TUNEL System; Promega, Madison, WI, USA) following treatment for $24 \mathrm{~h}$ with $100 \mu \mathrm{M}$ TN alone and in the presence of $10 \mathrm{mM} \mathrm{GSH}$ or $10 \mathrm{mM}$ L-NAC. In brief, subconfluent cell cultures were exposed to medium supplemented with $2 \%$ FBS according to different treatments for $24 \mathrm{~h}$ and fixed in $10 \%$ buffered formalin. Biotin-deoxyuridine (dU)-positive nuclei were counted on 10 fields with at least 100 cells in the same slide.

\section{Cell cycle analysis}

Cells were synchronised by $0.1 \mu \mathrm{g} \cdot \mathrm{mL}^{-1}$ colcemid (SigmaAldrich) treatment for $24 \mathrm{~h}$, and then kept in normal medium for 4 days before analysis. After treatment with $100 \mu \mathrm{M}$ TN for $6 \mathrm{~h}$, cells were washed in phosphate-buffered saline, fixed in ethanol and stained for $30 \mathrm{~min}$ at room temperature with $50 \mu \mathrm{g} \cdot \mathrm{mL}^{-1}$ propidium iodide (Sigma-Aldrich) in phosphatebuffered saline containing RNase. 10,000 events per sample were analysed by flow cytometry.

\section{Cytotoxicity and DNA adducts}

Cells were treated for different times and at different drug concentrations in the presence of $2 \%$ FBS. Cytotoxicity was assessed by MTT assay, using 3-(4,5-dimethylthiazol-2-yl)-2,5diphenyltetrazolium bromide (Sigma-Aldrich) and performed in quadruplicate, as previously described [17]. Normalised viability percentages were obtained according to the ratio $\left(A_{570}\right.$ mean values of extracts from exposed samples $/ A_{570}$ mean values of extracts from control cell samples) $\times 100$. DNA adducts were evaluated by high-performance liquid chromatography on DNA extracts from cells treated with $100 \mu \mathrm{M}$ TN for $16 \mathrm{~h}$ and are expressed as amount of 8-hydroxy-2deoxyguanosine per $10^{5}$ deoxyguanosines, as previously described [18].

\section{Nitrite production}

Cells were cultured in medium containing 2\% FBS and then stimulated with $100 \mu \mathrm{M}$ TN in medium containing $2 \%$ FBS. Nitrite production was determined by the Griess Reagent System (Promega).

\section{Immunoblotting}

After drug treatment, subconfluent cells were lysed in L-buffer ( $2.5 \%$ sodium dodecyl sulfate (SDS), Tris- $\mathrm{HCl} 250 \mathrm{mM} \mathrm{pH} 7.4)$ and $40 \mu \mathrm{g}$ of total cell lysates were loaded in reducing conditions. After separation on SDS-polyacrylamide gel electrophoresis and transfer to nitrocellulose filter (Protran; S\&S, Dassel, Germany), filters were probed with phospho-Akt $\left(\mathrm{Ser}^{473}\right)$, phospho-p70 S6 kinase $\left(\mathrm{Thr}^{389}\right)$, phospho-p38 MAPK $\left(\mathrm{Thr}^{180} / \mathrm{Tyr}^{182}\right)$, phosphoSAPK/c-Jun N-terminal kinase (JNK) $\left(\mathrm{Thr}^{183} / \mathrm{Tyr}^{185}\right)$, phosphoPTEN $\left(\mathrm{Ser}^{380} / \mathrm{Thr}^{382 / 383}\right.$ ), phospho-protein phosphatase (PP) $1 \alpha$ $\left(\mathrm{Thr}^{320}\right)$, Akt, p70 S6 kinase, p38, SAPK/JNK, PTEN, PP1 $\alpha$, PP2A and caspase- 8 antibodies (all from Cell Signaling Technology, Beverly, MA, USA), phospho-extracellular signal-regulated kinase (Erk) $1 / 2\left(\right.$ Thr $^{183} /$ Tyr $^{185}$ ) and $\alpha$-tubulin antibodies (both from Sigma-Aldrich), phospho-PP2A $\left(\mathrm{Tyr}^{307}\right.$ ) and poly(ADPribose) polymerase (PARP)-1 antibodies (from Santa Cruz Biotechnology, Inc., Santa Cruz, CA, USA). The signal was 

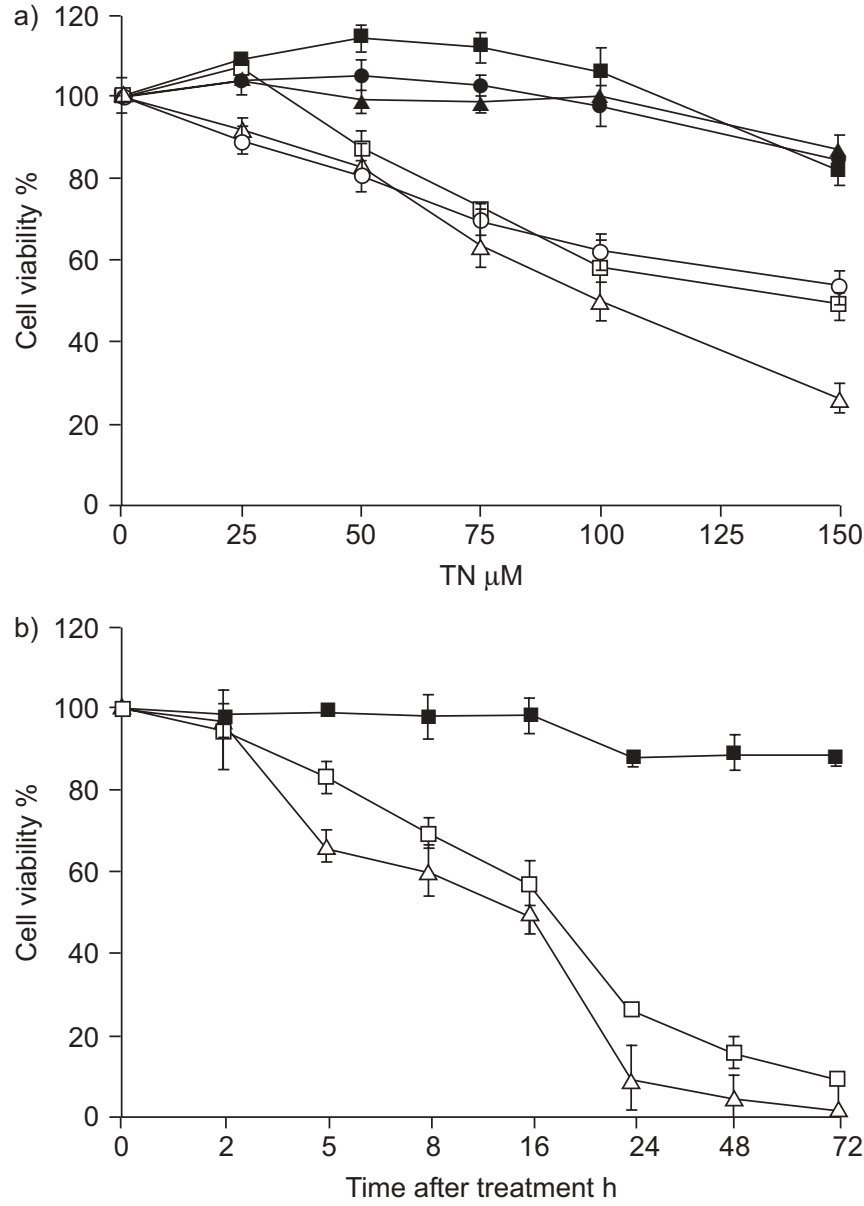

FIGURE 1. Taurolidine (TN) induces cell death in mesothelioma cells in a timeand dose-dependent manner. a) Viability (MTT) assay performed on human dermal

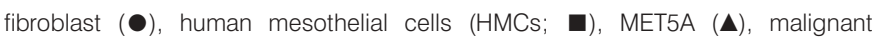
mesothelioma cell lines MMB $(\triangle)$ and MMP $(\square)$, and A549 cells $(\bigcirc)$ treated with TN $(25-150 \mu \mathrm{M})$, for $16 \mathrm{~h}$ in $2 \%$ fetal bovine serum medium. Filled symbols indicate non-neoplastic cells and empty symbols indicate neoplastic cells. The lineage of different cells are reported in the Methods section. b) Viability (MTT) assay performed at the indicated times on HMCs $(\mathbf{\square})$, and MMB $(\triangle)$ and MMP $(\square)$ cells treated with $100 \mu \mathrm{M} \mathrm{TN}$.

\begin{tabular}{|c|c|c|c|c|c|}
\hline \multirow[t]{3}{*}{ TABLE 1} & \multicolumn{5}{|c|}{$\begin{array}{l}\text { Cell cycle analysis of synchronised human } \\
\text { mesothelial cells (HMCs) and malignant } \\
\text { mesothelioma (MMB and MMP) cells upon } \\
\text { treatment with } 100 \mu \mathrm{M} \text { taurolidine (TN) for } 6 \mathrm{~h}\end{array}$} \\
\hline & \multirow[b]{2}{*}{ TN } & \multicolumn{4}{|c|}{ Cell cycle phase } \\
\hline & & Sub-G1 & G1 & s & G2-M \\
\hline \multirow[t]{2}{*}{ HMC } & - & $7.42 \pm 1.25$ & $56.67 \pm 4.02$ & $8.82 \pm 1.23$ & $27.32 \pm 2.43$ \\
\hline & + & $6.38 \pm 1.43$ & $58.21 \pm 3.98$ & $9.28 \pm 1.76$ & $26.21 \pm 2.76$ \\
\hline \multirow[t]{2}{*}{ MMB } & - & $3.65 \pm 0.97$ & $47.82 \pm 4.68$ & $18.61 \pm 1.98$ & $29.96 \pm 2.12$ \\
\hline & + & $40.05 \pm 3.01$ & $31.22 \pm 2.65$ & $16.38 \pm 1.97$ & $12.25 \pm 1.98$ \\
\hline \multirow[t]{2}{*}{ MMP } & - & $4.25 \pm 1.12$ & $57.28 \pm 4.12$ & $16.34 \pm 2.05$ & $26.32 \pm 2.87$ \\
\hline & + & $7.91 \pm 1.23$ & $53.84 \pm 3.01$ & $20.42 \pm 2.87$ & $18.01 \pm 1.96$ \\
\hline
\end{tabular}

Data are presented as average percentage of cells in cell cycle phase \pm SE.
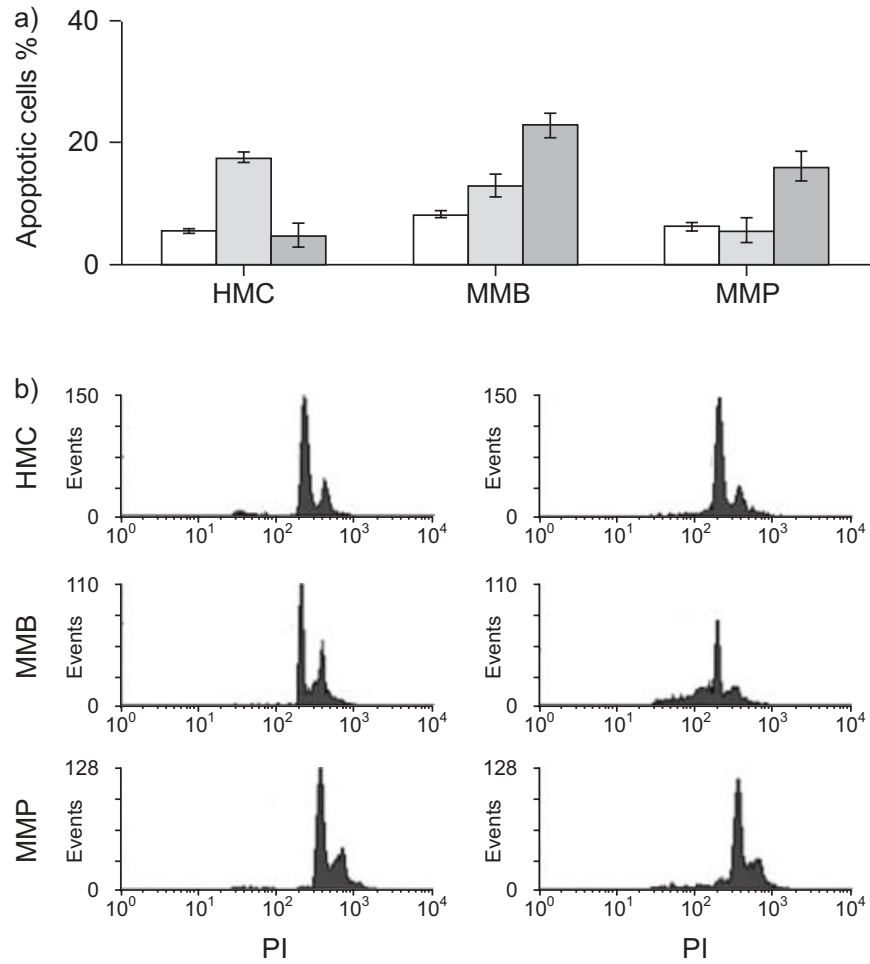

c)

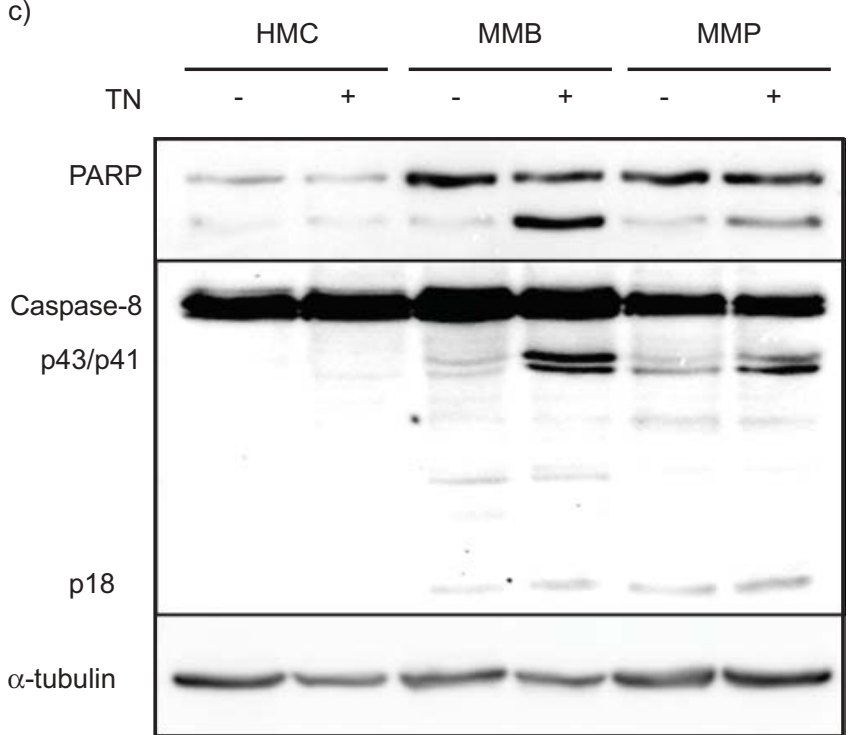

FIGURE 2. Taurolidine (TN) is pro-apoptotic in mesothelioma cells. a) Flow cytometry analysis of apoptosis in human mesothelial cells (HMCs), malignant mesothelioma MMB and MMP cells treated with $100 \mathrm{ng} \cdot \mathrm{mL}^{-1} \mathrm{CD}$ 95-activating antibody ( $\square$ ) or with $100 \mu \mathrm{M}$ TN for $24 \mathrm{~h}$ in $2 \%$ fetal bovine serum (FBS) medium $(\square)$ after annexin V/propidium iodide (PI) labelling. $\square$ : untreated cells as compared with $\alpha$ CD95 (CD95 activating antibody)- and TN-treated cells. b) Representative picture of flow cytometry cell cycle analysis, performed as reported in the Methods section on HMCs, and MMB and MMP cells either treated or not treated with $100 \mu \mathrm{M}$ TN for $6 \mathrm{~h}$ in $2 \% \mathrm{FBS}$. The percentages of cells in the different phases of the cell cycle are given in table 1. c) Immunoblotting analysis of poly(ADP-ribose) polymerase (PARP) cleavage and caspase- 8 activation on total cell lysates of HMCs, and MMB and MMP cells treated with $150 \mu \mathrm{M}$ TN for $6 \mathrm{~h}$ in $2 \%$ FBS. 
a)

\begin{tabular}{|c|c|c|}
\hline \multicolumn{3}{|c|}{$\mathrm{HMC}$} \\
\hline - & RP & $\mathrm{TN}$ \\
\hline$=$ & - & 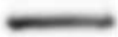 \\
\hline 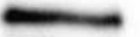 & & 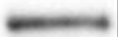 \\
\hline$\sim$ & - & $\longrightarrow$ \\
\hline 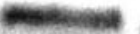 & $=:$ & Comonent \\
\hline
\end{tabular}

\begin{tabular}{|c|c|c|c|c|c|c|}
\hline \multicolumn{3}{|c|}{ MMP } & \multicolumn{3}{|c|}{ MMB } & \\
\hline- & RP & TN & - & $\mathrm{RP}$ & TN & \\
\hline & & $=$ & 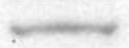 & sonemes & . & P-Akt \\
\hline 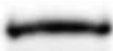 & & $m$ & $=$ & & 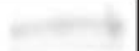 & P-p70 56 kinase \\
\hline$\overline{ }$ & & & 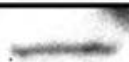 & 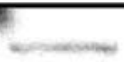 & - & Akt \\
\hline worvithy & 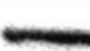 & siencents & 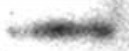 & 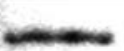 & juckoveds & p70 56 kinase \\
\hline & & & & & & $\alpha$-tubulin \\
\hline
\end{tabular}

b)

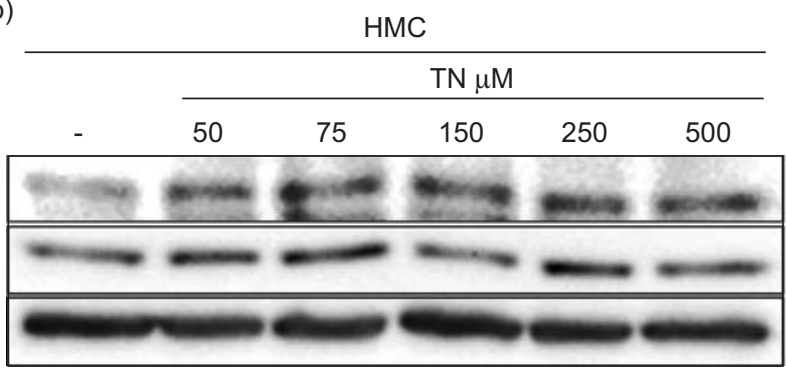

c)

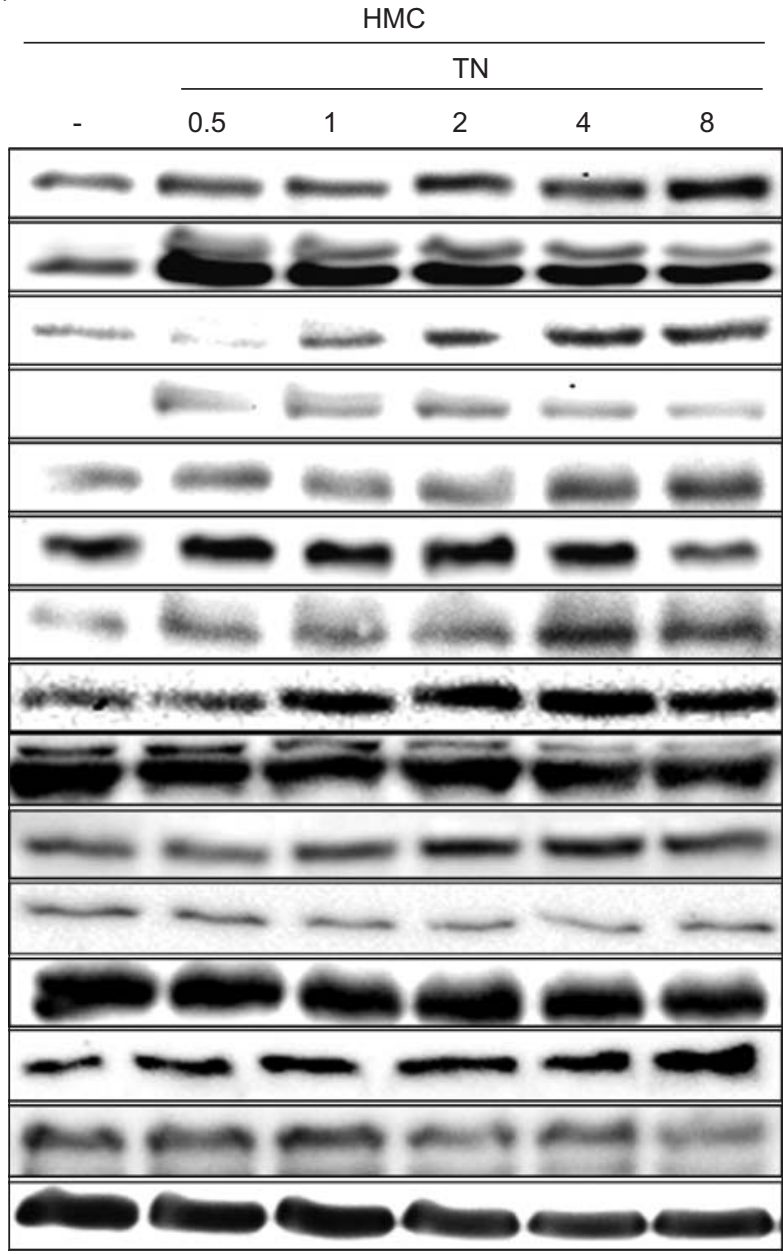

\begin{tabular}{|c|c|c|c|c|c|c|}
\hline \multicolumn{6}{|c|}{ MMP } & \\
\hline \multirow[b]{2}{*}{-} & \multicolumn{5}{|c|}{$\mathrm{TN} \mu \mathrm{M}$} & \\
\hline & 50 & 75 & 150 & 250 & 500 & \\
\hline & 200 & meneso & 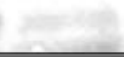 & & & P-Akt \\
\hline Hensese & - & $=$ & - & $=$ & - & Akt \\
\hline
\end{tabular}

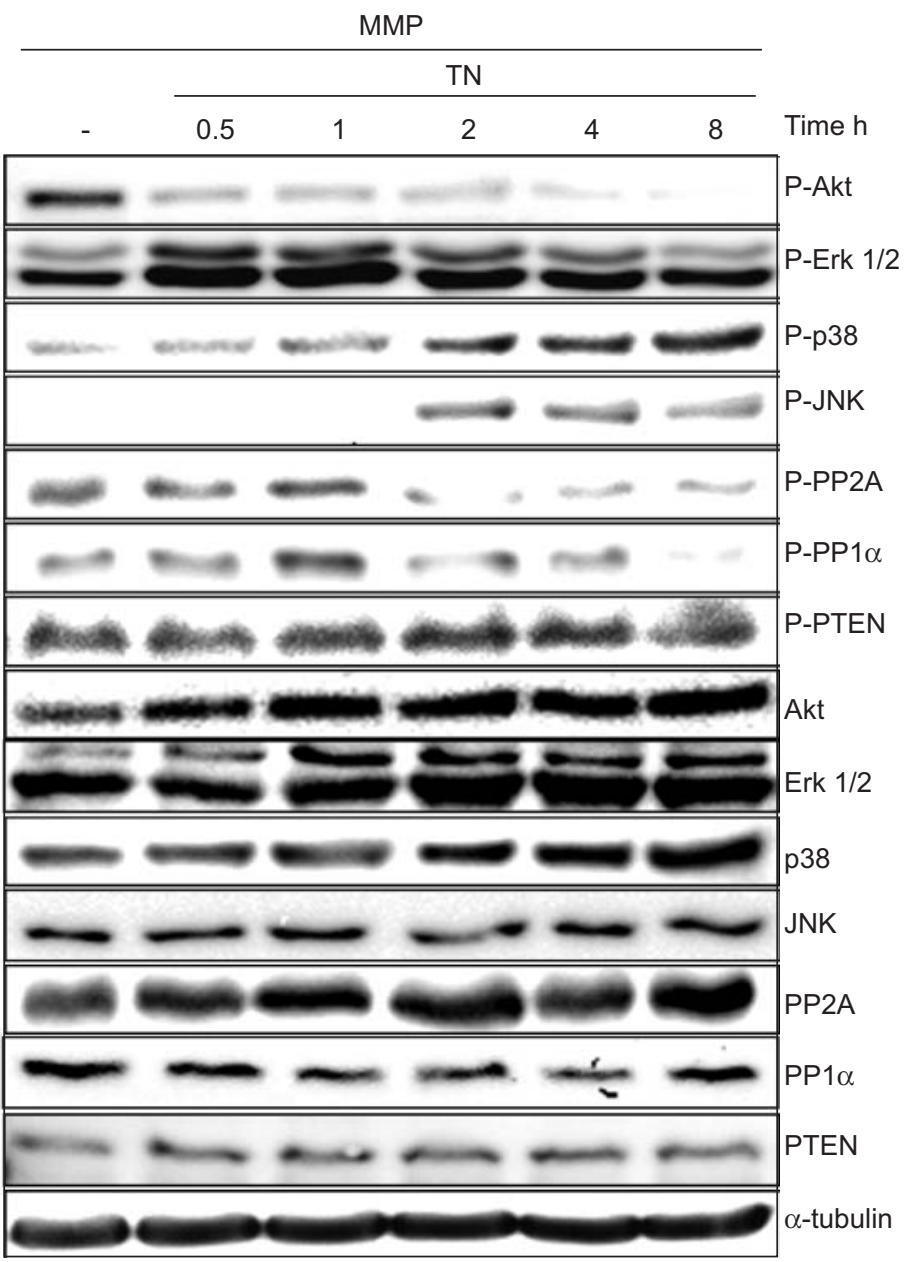




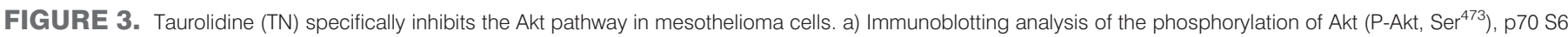

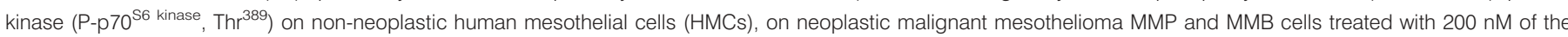

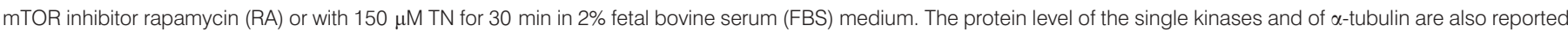

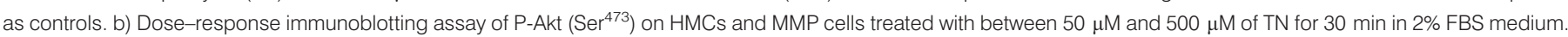

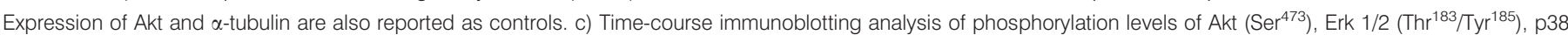

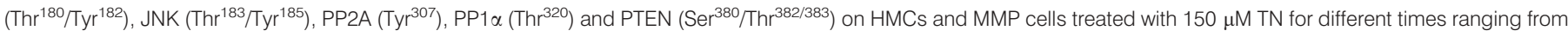
$30 \mathrm{~min}$ to $8 \mathrm{~h}$ in $2 \%$ FBS medium. The protein levels of the single effectors and of $\alpha$-tubulin are also reported as loading controls.

detected by the enhanced SuperSignal West Pico Chemiluminescent Substrate (Pierce, Rockford, IL, USA).

\section{Immunoprecipitation}

For immunoprecipitation, after drug treatment, total cellular proteins were extracted by RIPA buffer $(50 \mathrm{mM}$ Tris- $\mathrm{HCl} \mathrm{pH}$ 7.4, $150 \mathrm{mM} \mathrm{NaCl}, 0.5 \%$ sodium deoxycholate, $1 \%$ Triton $X-$ $100,0.1 \%$ SDS $)$ containing protease inhibitors $\left(10 \mu \mathrm{g} \cdot \mathrm{mL}^{-1}\right.$ aprotinin, $10 \mu \mathrm{g} \cdot \mathrm{mL}^{-1}$ leupeptin, $10 \mu \mathrm{g} \cdot \mathrm{mL}^{-1}$ pepstatin, $1 \mathrm{mM}$ phenylmethylsulfonyl fluoride) and phosphatase inhibitors (1 $\mathrm{mM} \mathrm{Na} \mathrm{NO}_{4}, 2 \mathrm{mM} \mathrm{NaF}$ ). For co-immunoprecipitation, after drug treatment, cells were lysed in solubilisation buffer (20 mM Tris- $\mathrm{HCl} \mathrm{pH} 7.4,5 \mathrm{mM}$ EDTA, $150 \mathrm{mM} \mathrm{NaCl}, 10 \%$ glycerol, $1 \%$ Triton $\mathrm{X}-100$ ) with protease and phosphatase inhibitors. 500- $\mu \mathrm{g}$ aliquots of clarified cell lysates were incubated with $1 \mu \mathrm{g}$ of antibody immobilised on protein-Asepharose $4 \mathrm{~B}$ packed beads (GE Healthcare, Piscataway, NY, USA) for $2 \mathrm{~h}$ at $4^{\circ} \mathrm{C}$. After extensive washes with lysis buffer, precipitated proteins were loaded in reducing conditions as described above. Filters were probed with Met (hepatocyte growth factor receptor) and platelet-derived growth factor receptor (PDGFR)- $\beta$ antibodies (both from Santa Cruz Biotechnology), phospho-tyrosine, p85, p110 $\alpha$ and nitrotyrosine antibodies (all from Upstate Biotechnology), Hsp-90 (from BD Biosciences, San Jose, CA, USA).

\section{Statistics}

Data from cytotoxicity, apoptosis and cell cycle cytofluorimetric analysis, nitrite production and DNA adducts are expressed as mean \pm SE of at least three independent experiments. Statistical differences were evaluated by ANOVA, followed by Tukey's honestly significant difference test. Values from TUNEL assay are expressed as percentages of positive nuclei over total counted. Statistical analysis was performed by Fisher's exact test. In all statistical evaluation, the significance threshold was specified in the text. All statistical tests were two-sided and calculated using Origin software (Microcal Software, Northampton, MA, USA).

\section{RESULTS}

\section{TN is cytotoxic and pro-apoptotic in mesothelioma cells}

Primary mesothelial (HMC), immortalised mesothelial (Met$5 \mathrm{~A}$ ) and mesothelioma cells (MMB and MMP) were treated with different concentrations of $\mathrm{TN}$, ranging from $25 \mu \mathrm{M}$ to $150 \mu \mathrm{M}$, for $16 \mathrm{~h}$ in low serum. Normal dermal fibroblasts and lung carcinoma cells were also treated as controls. A significant cytotoxic effect was observed at concentrations $>50 \mu \mathrm{M}$ in MMB, MMP and A549 neoplastic cells compared with nonneoplastic cells $(\mathrm{p}<0.001)$. MMB cells were more sensitive to $\mathrm{TN}$, while non-neoplastic cells, whether mesothelial or not in origin, displayed negligible cytotoxicity upon the same TN treatment (fig. 1a). The cytotoxic effect induced by $100 \mu \mathrm{M}$ TN was time-dependent, starting after $5 \mathrm{~h}$ of treatment $(\mathrm{p}<0.001)$ (fig. 1b).

TN-dependent programmed cell death was also examined. Mesothelioma cells, labelled with propidium iodide and annexin $\mathrm{V}$, were analysed for apoptosis by flow cytometry in the presence of TN. Moreover, given that Fas takes part in cell death pathways in mesothelioma [19], apoptosis has also been verified following agonistic CD95 antibodies (CH-11). A significant number of apoptotic cells was observed in mesothelioma cells treated with $100 \mu \mathrm{M}$ TN for $24 \mathrm{~h}(\mathrm{p}<0.001)$. However, apoptosis induced in MMB cells was far higher than that induced in MMP cells (fig. 2a). These results were confirmed by cell cycle analysis (fig. 2b), which revealed a significant increase in the sub-G1 population in MMB $(p<0.001)$ and MMP $(p<0.005)$ cells treated with TN. Moreover, treatment with TN induced a significant decrease in G2-M subpopulation in both mesothelioma cells compared with untreated cells $(\mathrm{p}<0.001)$ (table 1$)$.

To achieve a molecular characterisation of TN-induced apoptosis, PARP and caspase- 8 cleavage was determined by Western blotting on total cell lysates of HMCs, and MMB and MMP cells after 6-h treatment with $150 \mu \mathrm{M}$ TN. Under these conditions, TN induced a clear-cut cleavage of PARP and of caspase- 8 proteins in mesothelioma cells, as shown by the appearance of lower molecular weight bands (fig. 2c). Apoptosis, PARP and caspase- 8 cleavage or cell cycle alterations were not observed in non-neoplastic HMCs (fig. 2).

We conclude that TN specifically induces apoptosis of mesothelioma cells in a time- and dose-dependent manner. The lack of effects on non-transformed mesothelial cells prompted us to verify the mechanism of $\mathrm{TN}$ targeting to mesothelioma cells.

\section{TN inactivates Akt and activates PP2A in mesothelioma cells}

TN has been reported to affect several intracellular pathways and to inhibit protein synthesis [7]. As we and others have reported Akt as playing a key role in mesothelioma survival [4, $5,12]$, we verified in mesothelioma cells the effect of TN on the activity of Akt and its downstream p70 S6 kinase $\left(\mathrm{p} 70^{\mathrm{S} 6 \mathrm{~K}}\right)$ effector, a known regulator of translation. TN inhibited Akt and $\mathrm{p} 70^{\mathrm{S} 6 \mathrm{~K}}$ phosphorylation only in mesothelioma cells (MMP and $\mathrm{MMB}$ ), and not in non-neoplastic HMCs. On the contrary, the specific inhibitor of mTor, rapamycin, was effective in blocking the downstream p70 $56 \mathrm{~K}$ in all cells examined (fig. 3a). To verify Akt phosphorylation in cells resistant or sensitive to TN treatment, we compared non-neoplastic TN-resistant HMCs with TN-sensitive MMP mesothelioma cells displaying comparable levels of Akt protein. The inhibition of Akt activity 
by $\mathrm{TN}$ was dose-dependent, being evident at $50 \mu \mathrm{M}$ and reaching a maximum at $150 \mu \mathrm{M}$, whereas in HMCs Akt phosphorylation was totally unaffected (fig. 3b). The inhibitory effect of TN on Akt activity was also time-dependent, starting at $30 \mathrm{~min}$ and lasting for up to $8 \mathrm{~h}$ (fig. 3c). To verify the specificity of TN signalling inhibition, we also compared the activities of Erk 1/2, JNK and p38 by immunoblotting with phosphospecific antibodies on lysates of HMCs and MMP cells treated with TN with the same kinetics evaluated for Akt. Moreover, to get a better insight into the inhibitory effect induced by $\mathrm{TN}$, we examined the activities of two protein phosphatases and of one lipid phosphatase, which have been reported to regulate Akt [20]. Therefore, the phosphorylation of residues critical for the activity of PP2A (Tyr307), PP1 $\alpha$ (Thr320) and PTEN (Ser380, Thr382/383) phosphatases, all positively regulated by Ser/Thr or Tyr de-phosphorylation [21], was evaluated by immunoblotting with phosphospecific antibodies on non-neoplastic HMCs and on MMP cells. Regarding Erk 1/2 activity, beside of a sharp increase induced after $30 \mathrm{~min}$ of TN treatment in both cell types, no differences were observed thereafter, even upon prolonged $(8 \mathrm{~h})$ cell exposure to the drug. Conversely, JNK and p38 phosphorylation was increased by TN treatment both in HMCs and in MMP cells (fig. 3c). Analysis of the phosphatase activities revealed that PP2A became de-phosphorylated with a slower kinetics to those of Akt, with a significant activation from the second hour of treatment, indicating a progressive activation in phosphohydrolase activity upon TN. On the contrary, PP1 $1 \alpha$ showed a very late $(8 \mathrm{~h})$ and weak activation upon treatment with TN, whereas PTEN activity did not vary at all (fig. 3c). Similar findings were found in the MMB cell line (data not shown).

Moreover, we tested cytotoxicity elicited by TN on MMB cells expressing a myristoylated form of Akt (myrAkt-MMB), which is permanently localised to the plasma membrane and therefore constitutively active [22]. Surprisingly, no differences were observed between wild-type MMB and the same cells expressing active Akt in cell viability and in inhibiting Akt phosphorylation in a dose-dependent manner (data not shown).

Altogether, these results indicate that TN exerts a specific timeand dose-dependent inhibition on Akt activity only in mesothelioma cells, and not in normal mesothelial cells, and that PP2A jointly with PP1 $\alpha$ might be additionally involved in sustaining this process. The increase in JNK and p38 activities is also induced by TN treatment, but it is not specific for neoplastic cells.

\section{TN pro-apoptotic activity on mesothelioma cells is mediated by oxidative stress}

TN pro-apoptotic effect on glioma cells relies upon the generation of reactive oxygen intermediates [16] and oxidative stress can cause Akt inhibition in human leukaemia cells [15]. We verified whether the mechanism of TN pro-apoptotic activity in mesothelioma cells might be the activation of an oxidative pathway and whether this was responsible for TN biological effects.

The rate of oxygen free radical generation is changed by the production of nitric oxide. We evaluated nitrite production by
Griess assay, upon treatment of HMCs, as well as of MMB and MMP mesothelioma cells, with $100 \mu \mathrm{M}$ TN for different times ranging from $30 \mathrm{~min}$ to $24 \mathrm{~h}$. We observed a time-dependent nitrite production occurring early and only in mesothelioma cells, where the differences with mesothelial cells became significant $(\mathrm{p}<0.001)$ at between 2 and 4 h. In HMCs, only after $24 \mathrm{~h}$ was a significant level of nitrite production observed, which was lower than that of mesothelioma cells $(\mathrm{p}<0.001)$ (fig. 4a). To verify the oxidative-stress induced by $\mathrm{TN}$, we measured the amount of 8-hydroxy-2' deoxyguanosine (8-OHdG) DNA adducts, as a consequence of intracellular reactive oxygen species production [23]. Upon TN treatment, the fold increase of DNA adducts, normalised for $10^{5}$ 2'-deoxyguanosine molecules, was significantly higher in mesothelioma cells as compared with non-neoplastic mesothelial cells $(\mathrm{p}<0.001)$ (fig. $4 \mathrm{~b})$. These results confirm that mesothelioma cells are more sensitive to TN activity, which is mediated by oxidative stress.

Antioxidant agents have been widely used to prevent the effects elicited by oxidative stress in live cells [24]. We evaluated Akt phosphorylation in lysates from MMP cells pre-treated with $10 \mathrm{mM}$ GSH for $24 \mathrm{~h}$ before the addition of $150 \mu \mathrm{M}$ TN for $30 \mathrm{~min}$. GSH did not affect Akt phosphorylation in the absence of TN, whereas GSH cell pre-treatment completely prevented Akt inhibition by TN, suggesting that Akt dephosphorylation by $\mathrm{TN}$ is mediated via an oxidative response (fig. 4c). Similar results were obtained in a parallel experiment conducted using the antioxidant agent L-NAC (fig. 4c). These antioxidant agents did not alter TN-induced JNK and p38 activation (data not shown).

Cell viability was examined by MTT assay in cells treated for $24 \mathrm{~h}$ with increasing concentrations of $\mathrm{TN}$, after $24 \mathrm{~h}$ of pretreatment with $10 \mathrm{mM}$ GSH or $10 \mathrm{mM}$ L-NAC. Under these conditions, TN induced a dose-dependent decrease in cell viability, which is more pronounced than that observed after only $16 \mathrm{~h}$ (see fig. 1a). Pre-exposure of the same cells to the antioxidant agents significantly inhibited the cytotoxic effect of $\mathrm{TN}$, even at the highest concentration $(\mathrm{p}<0.001)$ (fig. $4 \mathrm{~d})$. The effect of antioxidants on apoptosis was also evaluated using TUNEL assay on MMP cells. A higher number (14.1\%) of biotin-dU-positive nuclei was observed upon cell exposure to $100 \mu \mathrm{M}$ TN for $24 \mathrm{~h}$ than in control nonstimulated cells $(3.1 \%)$. The concurrent treatment with $10 \mathrm{mM}$ GSH or $10 \mathrm{mM}$ L-NAC decreased the percentage of apoptotic nuclei to $2.6 \%$ and $3.1 \%$, respectively (fig. 4e). These differences were statistically significant $(\mathrm{p}<0.001)$. We obtained similar results for cell viability and apoptosis, with both antioxidant agents acting on the mesothelioma MMB cells (data not shown).

We conclude that the cytotoxic, pro-apoptotic effect of TN on mesothelioma cells, stems from oxidative stress, involves nitrite production and is reversed by general antioxidant agents.

\section{DISCUSSION}

Our results provide an explanation of the mechanisms underlying the anticancer effects exerted by TN on mesothelioma cells. The selective anticancer effect of TN has been focused on $[9,25]$ and its role for mesothelioma treatment has already been hypothesised $[26,27]$. The mechanism by which TN may 

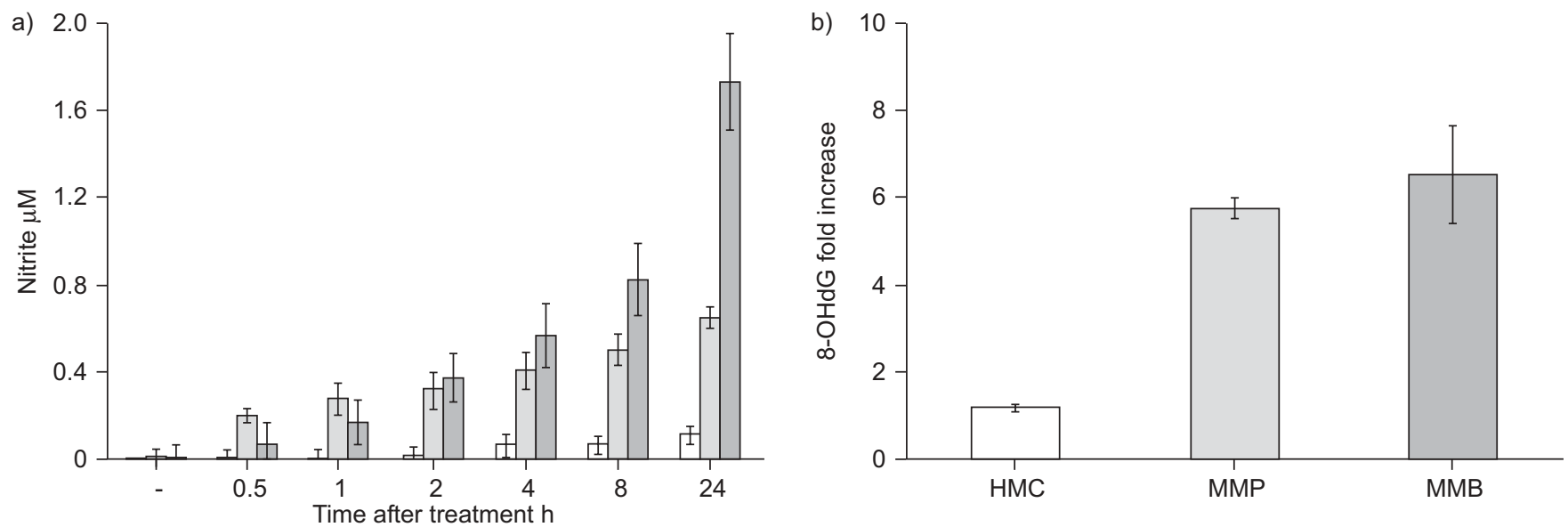

c)

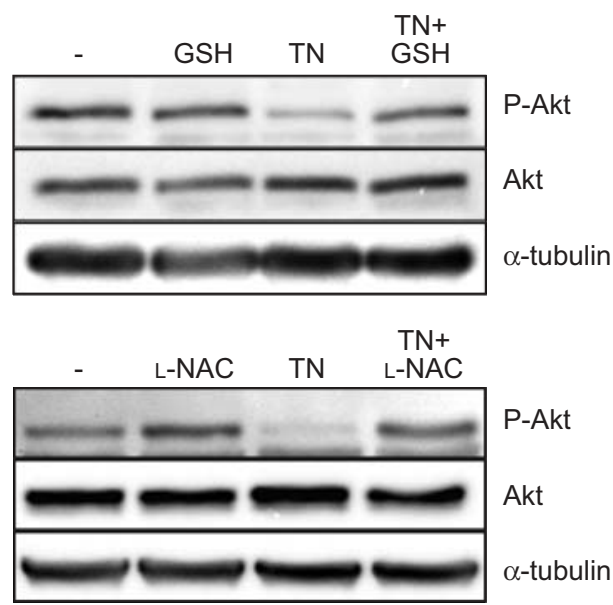

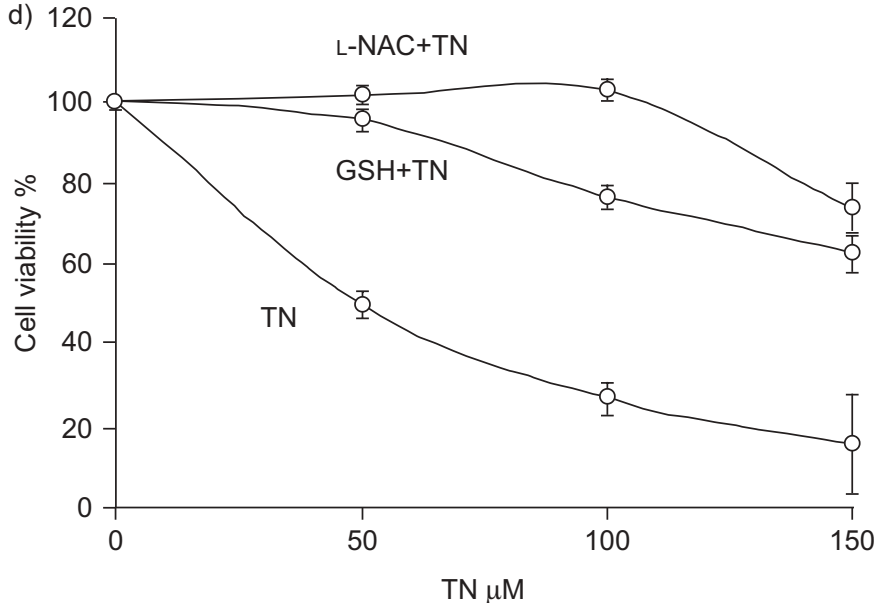

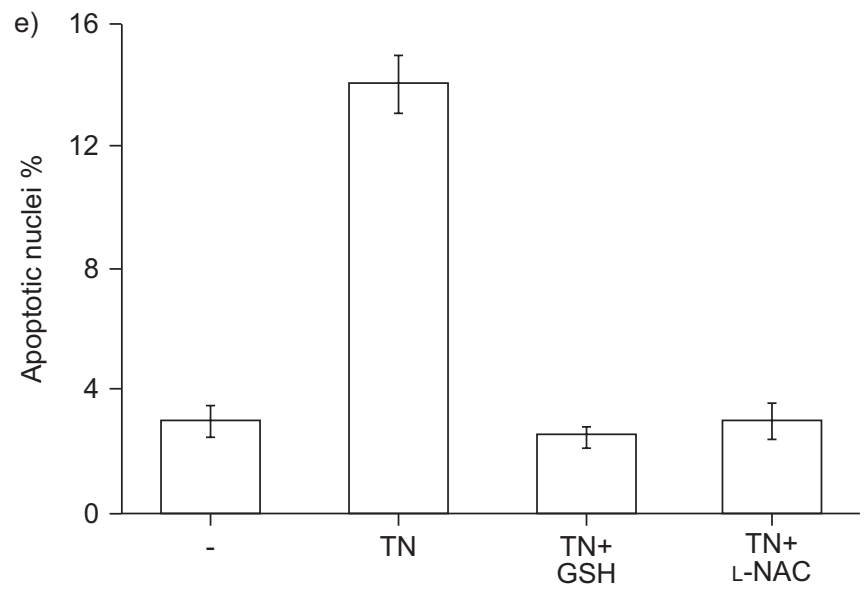

FIGURE 4. Taurolidine (TN) action on mesothelioma cells is mediated by oxidative stress. a) Griess assay for nitrite micromolar determination in human mesothelial cells (HMCs; $\square$ ), and malignant mesothelioma MMP $(\square)$ and MMB ( $\square$ ) cells treated with $100 \mu \mathrm{M} \mathrm{TN}$ at different times, ranging from $30 \mathrm{~min}$ to $24 \mathrm{~h}$, in $2 \%$ fetal bovine serum (FBS) medium. b) 8-Hydroxy-2-deoxyguanosine (8-OHdG) adduct determination in HMCs and MMP and MMB cells treated with $100 \mu \mathrm{M}$ TN for $16 \mathrm{~h}$ in $2 \%$ FBS. Data are reported as fold increase over the respective untreated sample. c) Immunoblotting analysis of phosphorylation of Akt (Ser ${ }^{473}$ ) in MMP cells in $2 \%$ FBS medium pre-treated for 24 h with

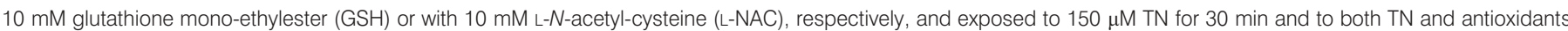
(upper panel, TN+GSH and lower panel, TN+L-NAC). Levels of Akt and $\alpha$-tubulin proteins are reported as loading controls. d) Dose-response viability (MTT) assay, performed on MMP cells in 2\% FBS medium with TN ranging from 50 to $150 \mu \mathrm{M}$ for $24 \mathrm{~h}$ or treated with TN at the same concentrations in presence of $10 \mathrm{mM}$ GSH or L-NAC. e) terminal deoxynucleotidyl transferase-mediated deoxyuridine triphosphate nick-end labelling (TUNEL) assay performed on MMP cells in $2 \%$ FBS medium, with $100 \mu \mathrm{M}$ TN for $24 \mathrm{~h}$, in either the presence or absence of GSH $10 \mathrm{mM}$ or L-NAC $10 \mathrm{mM}$. Percentages of apoptotic nuclei are shown, following counts on 10 fields with at least 100 cells on the same slide. 
provoke tumour cell death has been debated [8], but not yet clarified. We demonstrate herein that TN selectively induces mesothelioma cell death via oxidative stress and by negatively affecting Akt activity.

Given the crucial role played by Akt signalling in human tumours and in development, progression and chemo-resistance of mesothelioma, as previously shown by us $[4,5]$ and by others [12], we assessed whether TN could interfere with Akt activity. Our results clearly demonstrate that TN inhibits Akt signalling, as demonstrated by the relevant reduction of Akt and of downstream mTOR-dependent $\mathrm{p} 70^{\mathrm{S} 6 \mathrm{~K}}$ activities, but not of Erk $1 / 2$ activity. Following TN treatment, we observed in HMCs and in mesothelioma cells a clear and progressive increase of p38 and JNK activities, mostly involved in cell stress responses [28].

Conversely, sensitivity of mesothelioma cells to oxidative stress has been proposed as a potential therapeutic strategy [29], while others have suggested a cytotoxic effect of TN on glioma cells via oxygen intermediate-dependent apoptosis [16]. Others have demonstrated that $\mathrm{TN}$ also exerts oxidative stress on mesothelioma cells, with subsequent p53 activation and downregulation of survivin, Bcl-2 and Mcl1 survival proteins and cell death [27].

In the present study, we observed the effects of specific and time-dependent nitrite production upon mesothelioma cell treatment with TN. Interestingly, in both MMB and MMP cells, the kinetics of nitrite release is congruent with the time-course of cytotoxicity caused by this drug. Moreover, Akt inhibition also occurs after TN treatment, following a similar trend. Altogether, these results lead us to conclude that TN induces oxidative stress and this scenario is confirmed by the significant increase of $8-\mathrm{OHdG}$ adduct production induced by $\mathrm{TN}$ in mesothelioma cells compared with non-neoplastic mesothelial cells. This selectivity of TN action on mesothelioma cells was then further assessed by restoring cell viability when TN treatment was accompanied by either GSH or L-NAC. Both antioxidants rescue Akt activity inhibited by TN, highlighting the close association between TN-induced cytotoxicity and Akt de-phosphorylation.

In MMB cells expressing a myristoylated, constitutively active Akt [22], TN was still able to inhibit Akt phosphorylation and induce cytotoxicity, as in wild-type MMB cells. The fact that TN inhibited even constitutive activated Akt (albeit at higher concentrations) reinforces the specific effect of $\mathrm{TN}$ on this signalling.

Interestingly, PP2A activity was selectively increased upon TN treatment only in MMP but not in HMCs, with a peak starting $2 \mathrm{~h}$ after drug exposure, whereas $\mathrm{PP} 1 \alpha$ was activated very late and PTEN activity was not modified at all. The role of PP2A has been extensively studied as a modulator of signalling kinases and as a key regulator in human tumours [30]. Moreover, other studies reinforced that PP2A can be specifically targeted by pharmacological agents [31] and that this phosphatase specifically inhibits Akt activity [32]. Our results reveal a difference in timing of Akt inhibition and PP2A activation. We can hypothesise either that very low PP2A activity, below the immunoblotting detection threshold, may be sufficient to inhibit Akt in the early phases of cell response to $\mathrm{TN}$ or, more likely, that PP2A and possibly $\mathrm{PP} 1 \alpha$ sustain the
Akt inhibited status provoked by another yet unknown effector. It has recently been suggested that oxidative stress may influence Akt activity by nitration of the $\mathrm{p} 85$ subunit of phosphoinositide 3-kinase, leading to the impairment of the p85/p110 complex [33]. We observed no detectable nitration of the p85 regulatory subunit in mesothelioma cells upon treatment with TN (data not shown). Conversely, other studies reported that nitration may stimulate receptor tyrosine kinases (RTKs) leading to increase of Akt activity in rat fibroblasts [34]. However, we were not able to detect any modification of tyrosine phosphorylation levels of those RTKs most commonly expressed in mesothelioma cells, such as Met and PDGFR $\beta$ (data not shown). The discrepancy with our results may be due to cell lineage differences in responsiveness to oxidant agents. Our results strongly suggest that $\mathrm{TN}$ is acting on the mechanisms of Akt activation/inhibition more than on the upstream signalling. The chaperone heat-shock protein Hsp90 preserves Akt activity by preventing PP2A-mediated dephosphorylation [35]. Under the conditions of TN-induced inhibition of Akt, we observed no difference in Hsp90 or PP2A association with the kinase (data not shown). We conclude that another as yet unidentified mechanism underlies the observed effects of TN on Akt, comprising at least one early event (already occurring after $30 \mathrm{~min}$ of treatment), which might contribute to the observed apoptosis due to oxidative stress.

Locally injected TN in mice with intra-peritoneal mesothelioma exerted antitumour effects [26], suggesting that mesothelioma may be cured with TN via prolonged intra-pleural infusion. Our study provides a rationale for TN as a novel local treatment for malignant mesothelioma.

\section{SUPPORT STATEMENT}

Financial support was provided by the Buzzi Unicem Foundation for the study of Mesothelioma, Casale M., Italy, Mesothelioma Applied Research Foundation (MARF), Santa Barbara, CA, USA, the Regione Piemonte Ricerca Sanitaria Finalizzata, Torino, Italy, and the Associazione Italiana per la Ricerca sul Cancro (AIRC), Milan, Italy (funding to G. Gaudino).

\section{STATEMENT OF INTEREST}

None declared.

\section{ACKNOWLEDGEMENTS}

We thank Gruppo Italiano Mesotelioma (GIMe), Casale M., Italy, for logistic support. We also thank F. Boccafoschi (Dept of Clinical and Experimental Medicine, University of Piemonte orientale, Novara, Italy), A. Locatelli and S. Soligon (Dept DISCAFF, University of Piemonte orientale), for preliminary or complementary experiments, and M. Rinaldi (Dept DISCAFF), for advice on the statistical analysis.

\section{REFERENCES}

1 Pass HI, Vogelzang N, Hahn S, et al. Malignant pleural mesothelioma. Curr Probl Cancer 2004; 28: 93-174.

2 Carbone M, Emri S, Dogan AU, et al. A mesothelioma epidemic in Cappadocia: scientific developments and unexpected social outcomes. Nat Rev Cancer 2007; 7: 147-154.

3 Kroczynska B, Cutrone R, Bocchetta M, et al. Crocidolite asbestos and SV40 are cocarcinogens in human mesothelial cells and in causing mesothelioma in hamsters. Proc Natl Acad Sci USA 2006; 103: $14128-14133$. 
4 Cacciotti P, Barbone D, Porta C, et al. SV40-dependent AKT activity drives mesothelial cell transformation after asbestos exposure. Cancer Res 2005; 65: 5256-5262.

5 Bertino P, Marconi A, Palumbo L, et al. Erionite and asbestos differently cause transformation of human mesothelial cells. Int J Cancer 2007; 121: 12-20.

6 Treutner $\mathrm{KH}$, Bertram $\mathrm{P}$, Lerch MM, et al. Prevention of postoperative adhesions by single intraperitoneal medication. J Surg Res 1995; 59: 764-771.

7 Braumann C, Henke W, Jacobi CA, et al. The tumor-suppressive reagent taurolidine is an inhibitor of protein biosynthesis. Int J Cancer 2004; 112: 225-230.

8 Jacobi CA, Menenakos C, Braumann C. Taurolidine - a new drug with anti-tumor and anti-angiogenic effects. Anticancer Drugs 2005; 16: 917-921.

9 Stendel R, Stoltenburg-Didinger G, Al Keikh CL, et al. The effect of taurolidine on brain tumor cells. Anticancer Res 2002; 22: 809-814.

10 McCourt M, Wang JH, Sookhai S, et al. Taurolidine inhibits tumor cell growth in vitro and in vivo. Ann Surg Oncol 2000; 7: 685-691.

11 Braumann C, Stuhldreier B, Bobrich E, et al. High doses of taurolidine inhibit advanced intraperitoneal tumor growth in rats. J Surg Res 2005; 129: 129-135.

12 Altomare DA, You H, Xiao GH, et al. Human and mouse mesotheliomas exhibit elevated AKT/PKB activity, which can be targeted pharmacologically to inhibit tumor cell growth. Oncogene 2005; 24: 6080-6089.

13 Bertino P, Porta C, Barbone D, et al. Preliminary data suggestive of a novel translational approach to mesothelioma treatment: imatinib mesylate with gemcitabine or pemetrexed. Thorax 2007; 62: 690-695.

14 Bertino P, Piccardi F, Porta C, et al. Imatinib mesylate enhances therapeutic effects of gemcitabine in human malignant mesothelioma xenografts. Clin Cancer Res 2008; 14: 541-548.

15 Gao N, Rahmani M, Dent P, et al. 2-Methoxyestradiol-induced apoptosis in human leukemia cells proceeds through a reactive oxygen species and Akt-dependent process. Oncogene 2005; 24 3797-3809.

16 Rodak $\mathrm{R}$, Kubota $\mathrm{H}$, Ishihara $\mathrm{H}$, et al. Induction of reactive oxygen intermediates-dependent programmed cell death in human malignant ex vivo glioma cells and inhibition of the vascular endothelial growth factor production by taurolidine. J Neurosurg 2005; 102: 1055-1068.

17 Mosmann T. Rapid colorimetric assay for cellular growth and survival: application to proliferation and cytotoxicity assays. J Immunol Methods 1983; 65: 55-63.

18 Toyokuni S, Sagripanti JL. Association between 8-hydroxy-2'deoxyguanosine formation and DNA strand breaks mediated by copper and iron. Free Radic Biol Med 1996; 20: 859-864.

19 Stewart JHt, Nguyen DM, Chen GA, et al. Induction of apoptosis in malignant pleural mesothelioma cells by activation of the Fas
(Apo-1/CD95) death-signal pathway. J Thorac Cardiovasc Surg 2002; 123: 295-302.

20 Altomare DA, Vaslet CA, Skele KL, et al. A mouse model recapitulating molecular features of human mesothelioma. Cancer Res 2005; 65: 8090-8095.

21 Cantley LC, Neel BG. New insights into tumor suppression: PTEN suppresses tumor formation by restraining the phosphoinositide 3-kinase/AKT pathway. Proc Natl Acad Sci USA 1999; 96: $4240-4245$.

22 Ramaswamy S, Nakamura N, Vazquez F, et al. Regulation of G1 progression by the PTEN tumor suppressor protein is linked to inhibition of the phosphatidylinositol 3-kinase/Akt pathway. Proc Natl Acad Sci USA 1999; 96: 2110-2115.

23 Wu LL, Chiou CC, Chang PY, et al. Urinary 8-OHdG: a marker of oxidative stress to DNA and a risk factor for cancer, atherosclerosis and diabetics. Clin Chim Acta 2004; 339: 1-9.

24 Santangelo F. Intracellular thiol concentration modulating inflammatory response: influence on the regulation of cell functions through cysteine prodrug approach. Curr Med Chem 2003; 10: 2599-2610.

25 Ribizzi I, Darnowski JW, Goulette FA, et al. Taurolidine: preclinical evaluation of a novel, highly selective, agent for bone marrow purging. Bone Marrow Transplant 2002; 29: 313-319.

26 Nici L, Monfils B, Calabresi P. The effects of taurolidine, a novel antineoplastic agent, on human malignant mesothelioma. Clin Cancer Res 2004; 10: 7655-7661.

27 Opitz I, Sigrist B, Hillinger S, et al. Taurolidine and povidoneiodine induce different types of cell death in malignant pleural mesothelioma. Lung Cancer 2007; 56: 327-336.

28 Torres M, Forman HJ. Redox signaling and the MAP kinase pathways. Biofactors 2003; 17: 287-296.

29 Stapelberg M, Gellert N, Swettenham E, et al. Alpha-tocopheryl succinate inhibits malignant mesothelioma by disrupting the fibroblast growth factor autocrine loop: mechanism and the role of oxidative stress. J Biol Chem 2005; 280: 25369-25376.

30 Arroyo JD, Hahn WC. Involvement of PP2A in viral and cellular transformation. Oncogene 2005; 24: 7746-7755.

31 Janssens V, Goris J, Van Hoof C. PP2A: the expected tumor suppressor. Curr Opin Genet Dev 2005; 15: 34-41.

32 Ruvolo PP. Ceramide regulates cellular homeostasis via diverse stress signaling pathways. Leukemia 2001; 15: 1153-1160.

33 el-Remessy $\mathrm{AB}$, Bartoli $\mathrm{M}$, Platt $\mathrm{DH}$, et al. Oxidative stress inactivates VEGF survival signaling in retinal endothelial cells via PI 3-kinase tyrosine nitration. J Cell Sci 2005; 118: 243-252.

34 Esposito F, Chirico G, Montesano Gesualdi N, et al. Protein kinase $B$ activation by reactive oxygen species is independent of tyrosine kinase receptor phosphorylation and requires SRC activity. J Biol Chem 2003; 278: 20828-20834.

35 Sato S, Fujita N, Tsuruo T. Modulation of Akt kinase activity by binding to Hsp90. Proc Natl Acad Sci USA 2000; 97: 10832-10837. 